\title{
A new modified technique for the treatment of high-risk prethreshold ROP under the direct visual control of RetCam 3
}

\author{
Juraj Timkovic ${ }^{\mathrm{a}, \mathrm{b}, \mathrm{c}}$, Jan Nemcansky ${ }^{\mathrm{a}, \mathrm{c}}$, Dalibor Cholevik ${ }^{\mathrm{a}, \mathrm{b}, \mathrm{c}}$, Petr Masek ${ }^{\mathrm{a}}$, Rudolf Autrata ${ }^{\mathrm{b}}$, Inka Krejcirova ${ }^{\mathrm{b}}$
}

\begin{abstract}
Purpose. To describe a new modified technique in the treatment of ROP (retinopathy of prematurity) using the RetCam 3 digital imaging system - Camera-Assisted Laser photocoagulation and Cryotherapy of the Retina (CALCR).

Methods. From Nov 2011 to Oct 2013, 113 infants were diagnosed with ROP. The average post-conceptual age (PCA) at the time of diagnosis was the $35^{\text {th }}$ week of PCA; the average birth weight was 1,041 g. According to the ETROP study, the avascular part of the retina of infants with high-risk prethreshold ROP was treated with a trans-scleral diode laser or with cryotherapy within 48-72 $\mathrm{h}$ after the diagnosis. The intervention was performed under general anaesthesia under the direct visual control of the RetCam 3.

Results. The CALCR technique was used in all 23 infants ( 46 eyes) diagnosed with high-risk prethreshold ROP. The average age of these infants at the time of the intervention was the $38^{\text {th }}$ week of PCA. None of the infants had any serious complications during the CALCR procedure. In contrast to the traditional technique, CALCR offers many benefits: the image of the retina is real, magnified and not inverted, it shows details of the retina in a high resolution, photo and video documentation is available. Therefore the preoperative, intraoperative and postoperative condition of the retina can be precisely evaluated and compared on a fully standardized basis.

Conclusions. The CALCR procedure represents a new technique providing greater accuracy when targeting the avascular part of the retina, enables better visualisation and more precise treatment, and reduces the risk of unintended damage to healthy retinal tissue.
\end{abstract}

Key words: retinopathy of prematurity, laser photocoagulation, cryotherapy, RetCam photography

Received: January 14, 2015; Accepted with revision: May 15, 2015; Available online: July 3, 2015 http://dx.doi.org/10.5507/bp.2015.027

${ }^{a}$ Clinic of Ophthalmology, University Hospital Ostrava, Czech Republic

${ }^{b}$ Department of Pediatric Ophthalmology, Faculty of Medicine, Masaryk University, Brno and Faculty Hospital Brno

'Department of Craniofacial Surgery, Faculty of Medicine, University of Ostrava

Corresponding author: Juraj Timkovic, e-mail: timkovic.j@bluepoint.sk

\section{INTRODUCTION}

Retinopathy of prematurity (ROP) was first described in 1942 by Terry as greyish - white opaque retrolental membranes (retrolental fibroplasia). He assumed that the cause was a proliferation of the embryonic hyaloid system ${ }^{1}$. The term "retinopathy of prematurity" was first used by Health in 1953, who described three histopathological stages of this disease: primary retinal disease, secondary retinal disease from vitreous organization, and ocular atrophy as a result of reparative processes ${ }^{2}$.

According to the current concept, retinopathy of prematurity (ROP) is considered to be a vasoproliferative disease that mainly affects prematurely-born infants with a birth-weight below $1500 \mathrm{~g}$ and born before the $32^{\text {nd }}$ week of gestation. ROP is the most common cause of blindness in children in developed countries ${ }^{3,4}$. According to the ETROP study, cryotherapy and laser therapy of the peripheral avascular part of the retina are recommended as a standard treatment for Type 1 ROP. When the early stages of ROP with high risks are diagnosed, prompt treatment within 48-72 $\mathrm{h}$ is indicated. Laser therapy of the avascular part of the retina over a 360-degree range or cryotherapy under the direct visual control of an indirect ophthalmoscope are recommended as up-to-date techniques ${ }^{5-7}$. The efficacy of laser photocoagulation or the combination of cryotherapy and photocoagulation is about $80 \%$ in terms of anatomical success and about $75 \%$ in terms of functional success ${ }^{5,6,8}$.

Indirect ophthalmoscopy is considered to be the standard method for examining prematurely-born infants during ROP screening. The RetCam 3 digital imaging system is a modern alternative for the screening and diagnostics of retinal disorders in children. The possibility of taking photographs or recording a video during the examination, and having a wider view of the retina are the main benefits of this method of examination. This has been confirmed in many studies, which have demonstrated the higher sensitivity of using the RetCam 3 digital system in comparison to the conventional technique of indirect ophthalmoscopy ${ }^{9-11}$.

The aim of this paper is to describe a new modified technique for treating children with high-risk prethreshold ROP using the RetCam 3 digital imaging system - Camera-Assisted Laser photocoagulation and Cryotherapy of the Retina (CALCR). 


\section{METHODS}

From $1^{\text {st }}$ November 2011 to $31^{\text {th }}$ October 2013, a total of 380 prematurely-born infants (206 boys, 174 girls) were screened for ROP by an ophthalmologist. Their average gestational age at birth was 29.3 weeks (median: 30 weeks, $\mathrm{SD} \pm 2.15$, range 24-32 weeks) and their average birth weight was $1,331 \mathrm{~g}$ (median: $1,350 \mathrm{~g}, \mathrm{SD} \pm 417.61$, range $460-2,645 \mathrm{~g}$ ). All the ophthalmological examinations were performed through a dilated pupil (phenylephrine hydrochloride $2.5 \%$ eye drops + tropicamide $0.5 \%$ eye drops) and using an eyelid retractor (K1-5401 / K1-5677, Katen Products Inc., Denville, NJ, USA) with the use of local anaesthesia (oxybuprocaine hydrochloride $0.4 \%$ eye drops). The posterior segment of the eye was examined with the RetCam 3 digital imaging system (Clarity Medical Systems Inc., Pleasanton, CA, USA). According to the results and recommendations of the ETROP study, the avascular part of the retina of infants with a high-risk prethreshold stage of ROP was treated with a trans-scleral diode laser (IQ 810, Iridex, Mountain View, CA, USA) or with cryotherapy (Cryomatic Cryo, Keeler Instruments Inc., Broomall, PA, USA) within 48-72 hours of the diagnosis being made. The intervention was targeted to the avascular parts of the retina; direct treatment of the ridge and extraretinal fibrovascular proliferations were not performed. During the laser therapy, the technique of near confluent laser photocoagulation of the retina was used. The trans-scleral laser photocoagulation and cryotherapy were performed through the conjunctiva, a conjuctival incision was not necessary. The therapeutic intervention was performed in all prematurely-born infants under general anesthesia, through a dilated pupil (phenylephrini hydrochlordium $2.5 \%$ eye drops + tropicamidum $0.5 \%$ eye drops), using an eyelid retractor (K1-5401 / K1-5677 / K15340, Katena Products Inc., Denville, NJ, USA), under the direct visual control of the RetCam 3 digital imaging system (Clarity Medical Systems Inc, Pleasanton, CA, USA).

\section{RESULTS}

$113(29.7 \%)$ prematurely-born infants were diagnosed with ROP; all the cases were classified as stage 1 when the diagnosis was made. The average post conceptual age (PCA) of these infants at the time of diagnosis was the $35^{\text {th }}$ week of PCA (median: $34^{\text {th }}$ week of PCA, SD \pm 2.17 , range $30^{\text {th }}-40^{\text {th }}$ week of PCA); the average birth weight was 1,041 g (median: $990 \mathrm{~g}, \mathrm{SD} \pm 337.26$, range 460 $2,645 \mathrm{~g}$ ). The intervention (cryotherapy - 14 eyes / laser photocoagulation of the retina - 32 eyes) under the direct visual control of RetCam 3 was indicated and performed by an ophthalmologist in all 23 infants (20.4\%, 46 eyes) with high-risk prethreshold ROP (Fig. 1, 2). The average age of these infants at the time of the intervention was the $38^{\text {th }}$ week of PCA (median: $38^{\text {th }}$ week of PCA, SD \pm 2.58 , range $34^{\text {th }}-44^{\text {th }}$ week of PCA).; the average birth weight was $827 \mathrm{~g}$ (median: $850 \mathrm{~g}, \mathrm{SD} \pm 171.58$, range
$550-1,250 \mathrm{~g})$. The extent of the treatment corresponded with the standards and recommendations of the ETROP study in all children. The average number of laser spots that were used during the CALCR procedure was 260 spots per eye, the range of time per spot was $800-1,500$ $\mathrm{ms}$, the range of power used per spot was $900-1,500 \mathrm{~mW}$. The average number of cryo spots during the cryotherapy was 12 , the temperature at the tip of the cryoprobe was $-112{ }^{\circ} \mathrm{F}\left(-80{ }^{\circ} \mathrm{C}\right)$, the range of time was $4-5 \mathrm{~s}$ per spot. A mild conjunctival injection with chemosis and retinal / vitreous haemorrhages were relatively common but not serious complications. The retinal and vitreous haemorrhages resolved spontaneously within four weeks after the CALCR procedure (Fig. 3a, b). None of the infants had any intraoperative complications during the intervention under the direct visual control of RetCam3; therefore a switch to the conventional technique of treatment under the direct visual control of an indirect ophthalmoscope

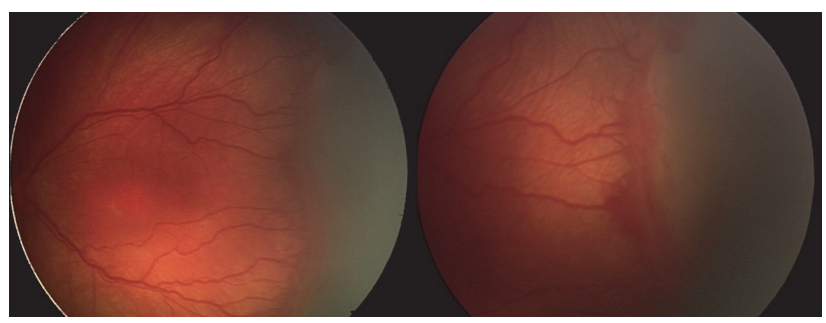

Fig. 1. Preoperative clinical findings of prematurely-born infant born in $25^{\text {th }}$ week of gestation, with a birth weight of 850 grams. Retinopathy of prematurity stage 3, zone II-III, plus disease. Images were taken in the $36^{\text {th }}$ week of PCA with the RetCam 3 digital imaging system.

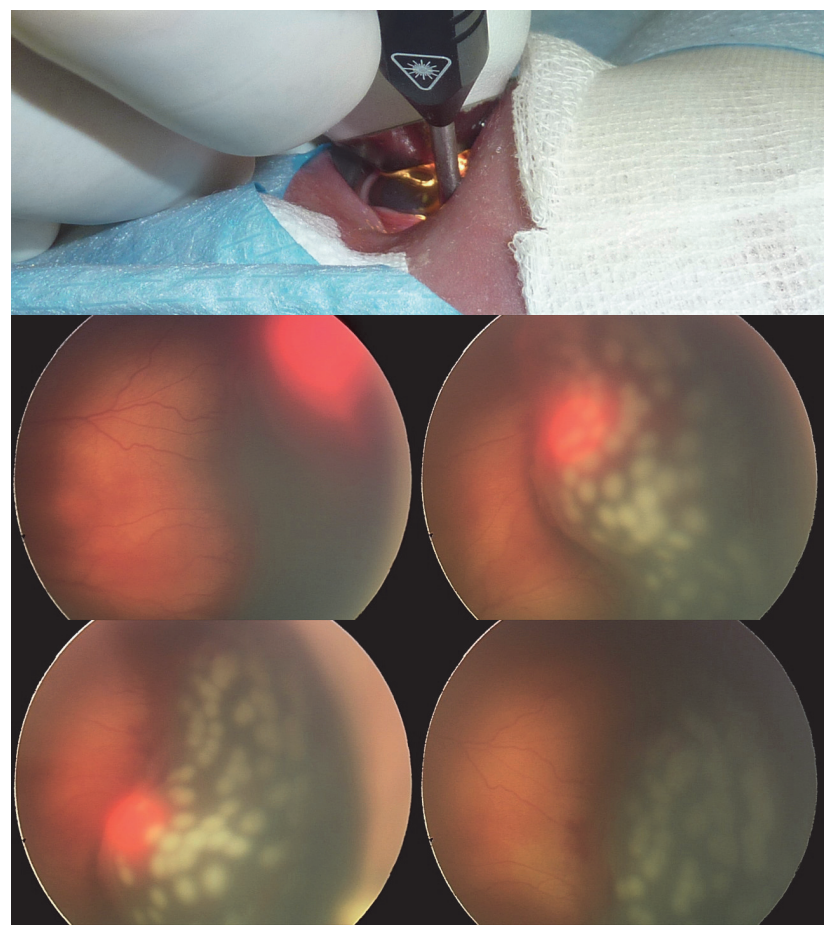

Fig. 2. CALCR treatment technique . Detailed images of the retina during the CALCR procedure. 
was not necessary. A minor difficulty of this new treatment technique was with the approach to the middle periphery of the retina with a cryo or laser probe at the points where the extraocular muscles attach and pass. We did not observe any other complications during the CALCR procedure. Unlike the traditional technique, which is performed under the direct control of an indirect ophthalmoscope, The CALCR procedure offers many benefits: the image of the retina during the intervention is real, magnified and not inverted, it shows details of the retina in highresolution, the possibility of scleral indentation and there is also a possibility of taking photographs or recording a video during the intervention. These benefits enable precise comparison of the preoperative, intraoperative and postoperative retinal findings.

\section{DISCUSSION}

The development and improvement of intensive neonatal care of premature infants requires enhanced ophthalmological care and its continuous improvement, following current trends that undoubtedly include the RetCam 3 digital imaging system. The system enables taking photographs and recording a video during the examination, comparing the images over time, monitoring the progress of the disease or the effects of the treatment. In addition to this, it enables connecting to a computer network, sharing and consulting relatively rare retinal findings with other pediatric ophthalmologists. Last but not least, it provides credible and defensible medical and legal documentation. Since November 2011, we have been also using this device for therapeutic interventions (the CALCR procedure). We have not found any similar usage of this system in the literature yet.

Using the CALCR procedure, we treated the avascular part of the retina outside the ridge and extraretinal fibrovascular tissue. There are different views on the direct treatment of the ridge between the vascular and avascular
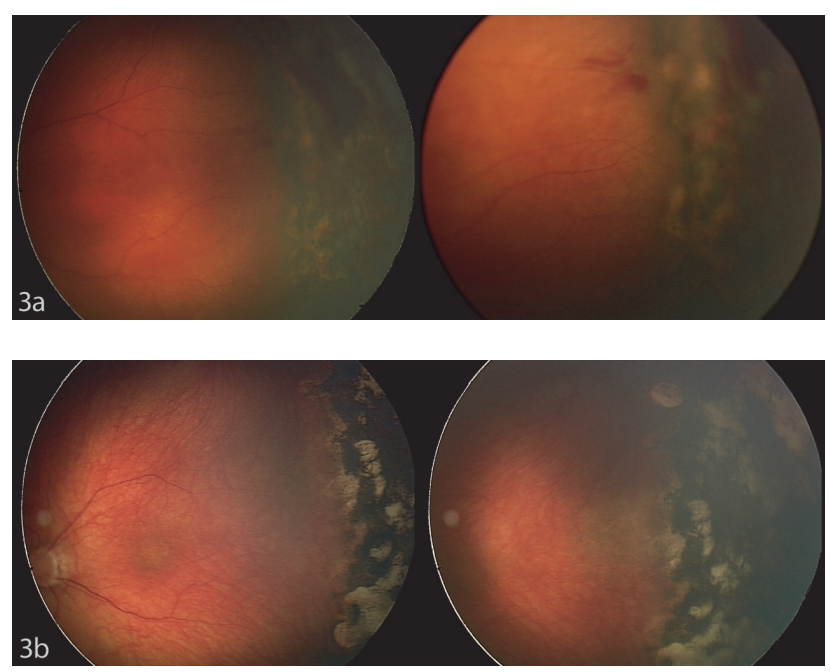

Fig. 3. Postoperative clinical findings two weeks (fig. 3a) and four weeks (fig. 3b) after the CALCR procedure. Images were taken with the RetCam 3 digital imaging system. parts of the retina ${ }^{8,12,12-20}$. Near confluent laser photocoagulation, which was used in the CALCR procedure, seems to be more effective than the usage of individual laser spots. None of the infants treated with the CALCR procedure required further intervention. A larger study involving more prematurely born infants with high-risk prethreshold ROP treated with both laser photocoagulation methods would be required for a more precise comparison. Studies confirm the current trend of using more dense forms of photocoagulation in the treatment of ROP (ref. ${ }^{14-16,21-23}$ ). When comparing the methods of single spots and near confluent photocoagulation, the method of dense laser photocoagulation seems to be more effective and safer ${ }^{23-25}$.

The complications of the CALCR procedure do not vary in principle from the complications that are described in standard methods of treatment with laser and cryocoagulation under the visual control of an indirect ophthalmoscope $\mathrm{e}^{12-16,19,20,22}$. In particular, we encountered a various extent of retinal and vitreous haemorrhages in all infants in our study group. None of the complications were serious, and they did not require any further intervention or treatment. The retinal and vitreous haemorrhages resolved spontaneously within four weeks after the CALCR procedure. None of the infants had any intraoperative complications during the intervention under the direct visual control of RetCam 3; therefore a switch to the conventional technique of treatment under the direct visual control of an indirect ophthalmoscope was not necessary.

A disadvantage of the CALCR technique is the more difficult approach to the posterior pole of the globe. This is caused by the anatomy of the eye. One possible solution for this relative complication is performing a conjunctival incision that enables us to reach the central parts of the retina with the laser probe. This problem occurs especially in the treatment of prematurely born infants with an aggressive or atypical form of ROP and with diagnosed retinal changes in zone I or at the border of zone I and II. A low therapeutical effect of the laser photocoagulation of the peripheral avascular parts of the retina was described in these forms of ROP. A relatively new method of intravitreal application of anti-VEGF appears to be a more promising treatment for infants with these types of aggressive and atypical forms of ROP (ref. ${ }^{26-27}$ ). We assume that this type of treatment will gradually replace the technique of the laser photocoagulation and will become the first-choice method for the treatment of these forms of ROP. Photocoagulation will probably remain the firstchoice method for the treatment of infants with ROP with changes in the anterior part of zone II. As we mentioned above, this area can be easily reached with the CALCR treatment technique without the need for conjunctival incision.

\section{CONCLUSION}

The laser photocoagulation and cryotherapy of the peripheral avascular part of the retina under the direct visual control of the RetCam 3 digital imaging system 
(CALCR) in prematurely-born infants with high-risk prethreshold ROP is a safe and effective technique in the treatment of ROP. This new modified technique for the treatment introduces greater accuracy when targeting the laser and cryo spots to the avascular part of retina, enables greater visualisation and treatment precision and reduces the risk of unintended damage to surrounding healthy retinal tissue. The possibility of taking a high-resolution photo-documentation of the retina enables the preoperative, intraoperative and postoperative condition of the retina to be precisely evaluated and compared on a fully standardized basis.

\section{ACKNOWLEDGEMENT}

Author contributions: JT, JN, DC, IK: literature search; JT, RA, IK: data collection; JT, JN, DC, RA, IK: data analysis and interpretation; JT, RA: statistical analysis; JT, RA, JN: conception and manuscript writing; JT, DC, RA, PM: final approval.

Conflict of interest statement: The authors state that there are no conflicts of interest regarding the publication of this article.

\section{REFERENCES}

1. Terry TL. Extreme Prematurity and Fibroblastic Overgrowth of Persistent Vascular Shealth Behind Each Crystalline lens. I. Preliminary report. Am J Ophthalmol 1942;25:203-4.

2. Health P. Pathology of retinopathy of prematurity, RLF. Am Ophthalmol 1953;34:1249-59.

3. Gilbert C. Retinopathy of prematurity: A global perspective of the epidemics, population of babies at risk and implications for control. Early Hum Dev 2008;84:77-82.

4. Steinkuller PG, Du L, Gilbert C, Foster A, Collins ML, Coats DK Childhood blindness. J Am Assoc Pediatr Ophthalmol Strabismus 1999:3:26-32.

5. The Early Treatment for Retinopathy of Prematurity Cooperative Group. The Incidence and Course of Retinopathy of Prematurity: Findings From the Early Treatment for Retinopathy of Prematurity Study. Pediatrics 2005;116:15-23.

6. The Early Treatment for Retinopathy of Prematurity Cooperative Group. The Early Treatment for Retinopathy Of Prematurity Study: structural findings at age 2 years. Br J Ophthalmol 2006;90:1378-82.

7. Elsas FJ, Collins M, Jones J, et al. Multicenter Trial of Cryotherapy for Retinopathy of Prematurity: Ophthalmological Outcomes at 10 Years. Arch Ophthalmol 2001;119:1110-8.

8. Autrata R, Senkova K, Holousova M, Helmanova I, Pyrochtova S Combined treatment with laser photocoagulation and cryotherapy for threshold retinopathy of prematurity. Eur J Ophthalmol 2008;18:112-7.
9. Balasubramanian M, Capone A Jr, Hartnett ME, Pignatto S, Trese MT. The Photographic Screening for Retinopathy of Prematurity Study (Photo-ROP): study design and baseline characteristics of enrolled patients. Retina Phila Pa 2006;26:S4-S10.

10. Capone A, Ells A, Balasubramanian M. The photographic screening for retinopathy of prematurity study (photo-ROP) - Primary outcomes. Retina- J Retin Vitr Dis 2008;28:S47-S54.

11. Salcone EM, Johnston S, VanderVeen D. Review of the use of digital imaging in retinopathy of prematurity screening. Semin Ophthalmol 2010:25:214-7.

12. Coats D, Miller A, McCreery K, Holz E, Paysse E. Involution of threshold retinopathy of prematurity after diode laser photocoagulation. Ophtalmology 2004;111:1894-8.

13. Harrell SN, Brandon DH. Retinopathy of prematurity: the disease process, classifications, screening, treatment, and outcomes. Neonatal Netw NN 2007;26:371-8.

14. Hubbard GB. Surgical management of retinopathy of prematurity. Curr Opin Ophthalmol 2008;19:384-90.

15. Arvas S, Sarici AM, Akar S. Diode laser photocoagulation posterior to the ridge in severe stage $3+$ threshold retinopathy of prematurity. Cutan Ocul Toxicol 2014;33:197-200.

16. Uparkar M, Sen P, Rawal A, Agarwal S, Khan B, Gopal L. Laser photocoagulation ( $810 \mathrm{~nm}$ diode) for threshold retinopathy of prematurity: a prospective randomized pilot study of treatment to ridge and avascular retina versus avascular retina alone. Int Ophthalmol 2011;31:3-8.

17. Ells A, Gole G, Hildebrand P, Ingram A, Wilson C, Williams R. Posterior to the ridge laser treatment for severe stage 3 retinopathy of prematurity. Eye 2013;27:525-30.

18. Gunn DJ, Cartwright DW, Gole GA. Prevalence and outcomes of laser treatment of aggressive posterior retinopathy of prematurity. Clin Experiment Ophthalmol 2014;42:459-65.

19. Jalali S, Azad R, Trehan HS, Dogra MR, Gopal L, Narendran V. Technical aspects of laser treatment for acute retinopathy of prematurity undertopical anesthesia. Indian J Ophthalmol 2010;58:509-15.

20. Parvaresh MM, Ghasemi Falavarjani K, Modarres M, Nazari H, Saiepour N. Transscleral diode laser photocoagulation for type 1 prethreshold retinopathy of prematurity. J Ophthalmic Vis Res 2013;8:298-302.

21. Banach MJ, Ferrone PJ, Trese MT. A comparison of dense versus less dense diode laser photocoagulation patterns for threshold retinopathy of prematurity. Ophthalmology 2000;107:324-7.

22. Gonzalez VH, Giuliari GP, Banda RM, Guel DA, Wingard M. Confluent laser photocoagulation for the treatment of retinopathy of prematurity. J Pediatr Ophthalmol Strabismus 2010;47:81-5.

23. Paysse E, Hussein M, Miller A, McCreery K, Coats D. Pulsed mode versus near-continuous mode delivery of diode laser photocoagulation for high-risk retinopathy of prematurity. J AAPOS 2007;11:388-92.

24. Tomcikova D, Prepiakova Z, Kostolna B, Gerinec A. Benefit of paint diode laser coagulation in the treatment of ROP. Cesk Slov Oftalmol 2011;67(4):115-8.

25. Prepiakova Z, Tomcikova D, Kostolna B, Gerinec A. Confluent diode laser coagulation: The gold standard of therapy for retinopathy of prematurity. J Pediatr Ophthalmol Strabismus 2015;52(1):43-51.

26. Autrata R, Senkova K, Holousova M, Krejcirova I, Dolezel Z, Borek I. Effects of intravitreal pegaptanib or bevacizumab and laser in treatment of threshold retinopathy of prematurity in zone I and posterior zone II - four years results. Cesk Slov Oftalmol 2012;68(1):29-36.

27. Autrata R, Krejcirova I, Senkova K, Holousova M, Dolezel Z, Borek I. Intravitreal pegaptanib combined with diode laser therapy for stage $3+$ retinopathy of prematurity in zone I and posterior zone II. Eur J Ophthalmol 2012;22(5):687-94. 